\title{
Research on the Status Quo and Countermeasures of Cultural Aphasia in College English Teaching
}

\author{
Rong Du \\ School of Foreign Studies, Xi'an University, 710065
}

Keywords: College English Teaching; Cultural Aphasia; Countermeasures

\begin{abstract}
With the development of China's economy and society, especially after the reform and opening up, the status of English in China's higher education system has been rising. It can be said that English teaching in universities in our country is established and grown up in the context of globalization. The process of globalization is the process of cultural integration and learning from each other. However, in our country's college English teaching, the introduction of western culture was over-emphasized, and the role of the country's culture was neglected, which led to the phenomenon of aphasia in the local culture in college English teaching. This article briefly introduces the connotation of cultural aphasia and the causes of cultural aphasia. It also gives the countermeasures to deal with the phenomenon of cultural aphasia in college English teaching.
\end{abstract}

\section{Introduction}

With the continuous deepening of globalization, English as an international language of exchange has increasingly attracted the attention of countries. Language is an organic part of culture. No language can exist independently from its own culture, and so does English. The process of English globalization is also the process of the spread of Western culture. The proper introduction of cultural teaching in college English teaching is understandable. After all, the study of language can not be separated from the construction of context, but the introduction of foreign culture is not to negate and dilute the national culture as a precondition, and it should not be the result.

After years of continuous development and improvement in English teaching in Chinese colleges and universities, it has achieved very significant results in many aspects of education and teaching. However, it is undeniable that with the advancement of college English teaching, the phenomenon of cultural aphasia has gradually become increasingly fierce. This has caused widespread concern among people of insight in the cultural and education sectors. How to overcome the phenomenon of cultural aphasia in English teaching in colleges and universities has not only been an education problem, but has evolved more towards social issues.

\section{The Connotation of Cultural Aphasia}

In terms of universality, the phenomenon of cultural aphasia refers to the fact that in Chinese college English teaching, teachers often focus their teaching on the expression of English related cultural and theoretical knowledge, while ignoring the organic fit of English with Chinese traditional culture. In other words, there is a lack of education-teaching orientation based on national cultural heritage in English teaching in the country. This kind of education and teaching model has led to a number of students who are fluent in English and can hardly state their own culture in English. Even some students think that foreign cultures are better than their own. This must be said to be a major flaw in the teaching of college English in our country, which is in obvious contradiction with the requirements of higher education in China and personnel training. We attach importance to the study and dissemination of our own culture and not to prevent the exchange of foreign cultures. On the contrary, we can only better communicate with foreign cultures on the premise of having an in-depth knowledge of our own culture.

Since the introduction of cultural aphasia, it has received widespread attention from the industry. In response to this situation, many colleges and universities are actively taking response measures, and English education workers in colleges and universities are gradually aware of the seriousness of 
the problem and are also giving remedial measures in varying degrees. However, on the whole, the phenomenon of cultural aphasia has not been significantly improved. Some scholars have conducted investigations and studies on the phenomenon of cultural aphasia among Chinese college students. The results show that Chinese college English learners are very strenuous in expressing traditional Chinese culture or expressing topics concerning traditional Chinese culture. It can be seen that the introduction of Chinese traditional culture in college English teaching in universities is obviously insufficient, and this phenomenon has gradually increased. In 2004, the Ministry of Education issued "Guidelines for Teaching English for College English", which has given guidance on this issue. It states clearly that efforts should be made to improve students' comprehensive cultural qualities in college English education and teaching.

\section{The Cause of Cultural Aphasia}

The causes of cultural aphasia in college English teaching are relatively complex, both at the social level and at the level of colleges and universities themselves, and even at the student level. This phenomenon is the result of the combination of factors. The author has been engaged in college English education and teaching for many years. I have been following up and studying the causes of this phenomenon for a long time. I personally concluded that the phenomenon of cultural aphasia in Chinese college English education and teaching is mainly caused by the following factors.

Deviations in Understanding of Cultural Exchanges. It is undeniable that under the tide of globalization, China cannot and should not be alone, but should participate in globalization from a deeper level and a wider area. In the process of globalization, it is unavoidable to have different cultural exchanges, and such exchanges are of course two-way. We must not only understand the outside world, but also let the outside world know about us. Different cultural exchanges do not simply cater to one side and ignore the other, let alone give up a certain position and social identity. In this regard, many people still have misunderstandings. In their thinking, college English learning is to receive Western culture. Based on this, many of them did not use traditional Chinese culture as an integral part of education and teaching, or even as a link. At the same time, in the tide of globalization, western culture relied on films, literature, songs and other carriers to launch a round of impact on Chinese cultural positions. In comparison, our propaganda and use of traditional culture are obviously at a disadvantage. This has led many people to have the illusion that Western culture has stronger vitality and more lasting spread. This soft power of culture has gradually eroded and invaded our college positions. Under such powerful impact, many teachers and students have gradually been affected by their world outlook, outlook on life and values, thus giving up their ability to defend their own culture in the field of thought.

The Lack of Local Culture in the Curriculum. Looking at our country's college English course system, whether it is in the selection of teaching materials or in the curriculum setting, we ignore the involvement of local culture. In the selection of college English textbooks, English textbooks used in many colleges and universities are now published by Anglo-American Press. The content of textbooks inevitably introduces foreign customs, cultural geography and other contents. The introduction of Chinese traditional culture is minimal. In non-English majors' compulsory and elective course materials, the introduction of cultural conventions in Western countries is basically full. In addition to the Chinese majors, there are few courses on Chinese culture in the curriculum setting of universities. This set of courses obliges to separate the relationship between college English and traditional Chinese culture. Many students' understanding of traditional Chinese culture is only on the surface and they only know a few words and can't understand and appreciate their traditional culture.

Mistargeting the Relationship Between Mother Tongue and Foreign Language Learning. As mentioned earlier, many people mistakenly believe that if they are completely free from the shackles of their own language and culture, they can really master another language. Based on this understanding, many colleges and universities have deliberately removed the influence of cultural factors in their own country during the course of college English education. They mistakenly regard context as the only and core factor in foreign language learning, and mistakenly turn a blind eye to 
cultural factors' promotion of language learning. This narrow understanding of language learning does not exist in a small number of people, but rather has a considerable group basis. Since the modern times, foreign language learners in our country have gathered a great deal and they all attach great importance to the study of their own culture and native language, whether in the field of translation or cultural exchange. The promotion of foreign language learning by native language and native culture may not be particularly obvious for beginners. However, as the study continues to deepen, you will find that the language of each country is actually interlinked. Any idea or practice that cuts the link between culture and language and separates the connections between different languages is very wrong.

\section{Research on the Countermeasures of Cultural Aphasia in College English Teaching}

To solve the phenomenon of cultural aphasia in college English teaching requires the joint efforts of the whole society. Languages carry culture. The purpose of learning English is not only to master knowledge and a communication tool, but more importantly to realize the extensive exchange and mutual promotion of Chinese culture and other cultures. If there is a phenomenon of cultural aphasia in English teaching in colleges and universities, it means that the loss of Chinese cultural influence and the unbalanced communication. To solve the current phenomenon of cultural aphasia in college English teaching, we should focus on the following aspects.

Correctly Understand the Status of Chinese Culture in English Teaching. Although there has been a long history of raising the status of Chinese culture in English teaching, this issue has not been properly resolved. The status of Chinese culture in English teaching in universities is still relatively vague. Many college English majors have clear requirements for English language learning and cultural background knowledge, but the requirements for Chinese traditional culture are not specified. The position of Chinese culture in English teaching in universities is the premise and foundation for solving the phenomenon of cultural aphasia in college English teaching. Only the correct understanding of Chinese culture can enable teachers and students face this issue, and it is really touched them from their heart.

Plan the Curriculum Scientifically. The scientific planning curriculum system plays an important role in solving the problem of aphasia in English teaching and learning in colleges and universities. The curriculum system consists of many factors, such as the selection of teaching materials, the study of teaching methods, and the construction of assessment methods. First of all, we should scientifically and reasonably select and compile corresponding teaching materials based on the actual teaching. In the initial learning, students first start with teaching materials. We should not introduce foreign teaching materials in a unified manner. Instead, we should use teaching objectives as the traction, select and compile teaching materials that are suitable for the construction and development of the profession, and ensure the smooth development of the education and teaching process. Secondly, we must gradually set up independent traditional cultural courses in the course of curriculum design so that we can take care of both inside and outside, and minimize the chance of losing sight of one another. Finally, we should build a scientific and rational evaluation system based on the objectives of education and teaching. Whether or not the teacher's teaching goals are achieved and whether the student's learning effect is consistent with expectations will require feedback from the results of this evaluation system. In this system, through the evaluation of students by teachers, we understand the insufficiency of teachers in education and teaching, thus improving education and teaching methods, enriching the content of education and teaching, and strengthening education and teaching management. Through the assessment of students by teachers, students' learning priorities are adjusted to find out the insufficiency in students' knowledge and abilities, so that students' learning of Chinese culture is no longer merely superficial.

Take Flexible and Varied Teaching Methods. Many English teachers graduate from the normal colleges. In a strict sense, they belong to liberal arts. This has led to a slight lack of mastery of the Internet and informationization for college English teachers. They sometimes have their own opinions on the improvement of teaching, but they suffer from no corresponding means of realization. For example, new informatization such as admiring lessons and inverting classroom 
teaching, and teaching methods under the new media environment basically need technical means as a support. However, liberal arts teachers are obviously weak in this respect and there is no technical means to put the idea into practice. Diverse and informatized teaching methods can display traditional culture in English teaching in a flexible manner, which can greatly arouse the enthusiasm and initiative of the majority of students. At the same time, English learning under informatization conditions can be seamlessly connected with Chinese traditional culture so that the two can complement and promote each other.

\section{Conclusion}

In the increasingly widespread and close international exchange today, we recognize the importance of learning English while we cannot ignore the understanding and learning of our own culture. In international exchanges, it is of course indispensable to absorb, but going out is sometimes more important. We must face up to the phenomenon of cultural aphasia that exists in college English teaching. We will continue to study and continuously improve it, and ultimately achieve the perfect combination of college English teaching and the two-way communication of culture.

\section{Reference}

[1] X. Tao. Analysis of Cultural Aphasia in English Education in Colleges and Universities in China [J]. Journal of Shanxi Normal University(Social Science Edition). 2014, 41(1): 216-217.

[2] D. Y. Wang. The Current Situation of "Aphasia in Chinese Culture" in College English Education [J]. Journal of Heilongjiang Institute of Education. 2015, 34(3): 16-17.

[3] K. Zhao. Analysis of Chinese Culture's Aphasia in English Education in Colleges and Universities: Response Measures [J]. Teaching Practice, 2016(81): 53-56.

[4] L. F. Xiao and L. Li. The Current Situation of "Aphasia in Chinese Culture" in English Education in Chinese Universities [J]. Foreign Language Teaching Theory and Practice, 2010(1): 39-47.

[5] Q. C. Huang. A Review of Researches on "Aphasia in Chinese Culture" in Domestic English Education [J]. Journal of Zunyi Teachers College, 2011, 01(28): 40-42.

[6] L. J. Qiao. Research on "Chinese Culture Aphasia" in Foreign Language Education in Chinese Universities [J]. Journal of Zhejiang University of Traditional Chinese Medicine, 2013, 12(16): 1443-1445.

[7] K. H. Qiao. Chinese Culture Aphasia and Coping Strategies in College English Education [J]. Journal of Chinese Literature(Foreign Language Education Teaching), 2014, 04(21): 123-124.

[8] S. M. Ye. An Experimental Research Program for Improving the Phenomenon of "Chinese Culture Aphasia" by Adding Chinese Cultural Courses in College English Majors [J]. Youth Years, 2013.

[9] Q. H. Liu. A Study of Aphasia in Chinese Culture in College English Education [J]. Social Science, 2017(01). 